\title{
Morphological evidence for a subpopulation selection effect by estrogen and antiestrogen treatments in the heterogeneous MCF-7 cell line
}

Jacqueline Palmari ${ }^{\mathrm{a}, *}$, France Wallet ${ }^{\mathrm{b}}$, Julien Berard $^{\mathrm{b}}$, Yolande Berthois ${ }^{\mathrm{b}}$, Pierre Marie Martin ${ }^{\mathrm{b}}$ and Christophe Dussert ${ }^{\mathrm{b}}$

${ }^{\text {a }}$ Département de Physique des Interactions Photons-Matière, case ECI, Faculté des Sciences de St Jérôme, 13397, Marseille Cedex 20, France

${ }^{\mathrm{b}}$ Laboratoire de Cancérologie Expérimentale, IFR Jean Roche, Faculté de Médecine Secteur Nord, Boulevard Pierre Dramard, 13916 Marseille Cedex 20, France

Received 6 October 1999

Accepted 3 March 2000

Recently, we developed a method to quantitatively study tumour cell heterogeneity in terms of both nuclear size and estrogen receptor (ER) content by image cytometry. The method, previously used to analyse the proliferation of the breast cancer cell line MCF-7, was applied here to analyse the growth of this cell line under estradiol (E2), hydroxytamoxifen (OH-TAM), and both E2 and OH-TAM treatments. The method extracts characteristic parameters of single nuclei and features that measure the global and local organisation of the cells in their growing phase. Modifications of the heterogeneity of the cell line are emphasised through phenotypic changes and modifications of the spatial organisation of the cells. The hormone (E2) generates a very fast growth of cells with small nuclei that became ER negative in the long term. The antihormone (OH-TAM) produces a gradual selection of ER negative or poorly positive cells with large nuclei. These modifications are reversed when E2 and OH-TAM are simultaneously used. Moreover, estradiol induces a permissive context of proliferation, whereas hydroxytamoxifen acts

\footnotetext{
${ }^{*}$ Correspondence to: Dr Jacqueline Palmari, Laboratoire de Cancérologie Expérimentale, Faculté de Médecine Secteur Nord, Boulevard Pierre Dramard, 13916 Marseille Cedex 20, France. Tel.: +33 4916988 82; Fax: +33 4910901 71; E-mail: palmari.j@jeanroche.univ-mrs.fr.
}

only on some subpopulations. The combination of cell count, cytomorphology, and cell organisation revealed the magnitude of the potential of structuration of hormones or antihormones on in vitro growing cells.

Keywords: Breast cancer cell, phenotypic alterations, image analysis, topographical analysis

\section{Introduction}

Estrogen receptor (ER) status in breast cancer is considered to indicate the hormonal sensitivity of cancer cells $[28,32]$. Although ER is used for the selection of patients with advanced disease who might benefit from hormono-therapy, a large number of breast tumours (40-50\%) fail to respond to endocrine therapy, in spite of the presence of functional ER [6,17,23]. Breast cancer involves a conglomeration of biologically heterogeneous entities since ER-positive tumours are made up of positive and negative cells. Positive cells are not uniformly distributed and ER expression differs from one cell to another within a given tumour. Evaluation of heterogeneity is critical for analysing tumour behaviour in response to therapy $[19,31]$ and for explaining the lack of correlation between responsiveness and marker levels that often arises. While the importance of evaluating cell heterogeneity has been recognised, diverse strategies have evolved for its characterisation. Flow cytometry and immunocytochemistry allow assessment of heterogeneity for individual or multi markers $[14,15]$. Quantification by image analysis in situ of estrogen receptor immunochemistry (ERICA) provides a reproducible means of characterising receptor heterogeneity $[2,4,26,36]$. In all these studies, labelling intensities were heterogeneous. Subpopulations have been demonstrated to exist, but spatial heterogeneity is never considered. Since, the po- 
sition and organisation of cell subpopulations strongly depend on the nature and the strength of the interactions between them, the analysis of the spatio-temporal patterns of these cells could contribute to a better understanding of these interactions [3].

We previously developed an assay that simultaneously measures ER content and nuclear size of cells. This assay was used to study the heterogeneity in growing MCF-7 cells [29]. Our goal was to compute not only features of single nuclei, but also to extract features containing information on the structural organisation of the proliferating cells, since these features describe the relationships between cells. This latter analysis gives us three kinds of information leading to a multiscale analysis: degree of order of the cell population, analysis of the clones formed by the cells and finally a structural evaluation of the global evolution of the subpopulations. In the present study, we analysed the proliferation of MCF-7 cells under estradiol (E2), hydroxytamoxifen (OH-TAM), and both $\mathrm{E} 2$ and $\mathrm{OH}-$ TAM treatments. The aim was (i) to compute proliferation indexes extracted from cell measurements on the whole population or on subpopulations, (ii) to do multiparametric characterisation on cell nuclei from ERICA images (ER content and nuclear area) and from Feulgen stained images (characteristic parameters of the chromatin condensation), (iii) to measure global and local order or disorder of the cell structural organisation and to correlate it to the other parameters. Modifications of the degree of heterogeneity of the cell line under treatments are evidenced through phenotypic changes and modifications of the spatial organisation of the cells. Our results show that it is essential to consider the MCF-7 cell line as a "plastic" cell line whose heterogeneity could be pharmacologically modulated and that the dynamic evolution analysis of both subpopulation ratios and spatial organisations is a way to interpret the overall effect of drugs on the cell population.

\section{Materials and methods}

\subsection{Cell culture and treatments}

MCF-7 cells were obtained from Dr M. Lippman (NIH, Bethesda, MD) [37] and maintained in 50\% Dulbecco's minimum essential medium-50\% Ham's F12 (DMEM/F12; Gibco, Grand Island, NY) supplemented with $16 \mathrm{ng} / \mathrm{ml}$ of insulin, $2 \mathrm{mM}$ L-glutamine, $0.06 \%$ HEPES buffer, and $10 \%$ heat-inactivated fetal calf serum depleted of steroids by dextran-charcoal treatment (FCDCS). Cells were plated in T-75 flasks and cultured at $37^{\circ} \mathrm{C}$ in a $95 \%$ air $/ 5 \% \mathrm{CO}_{2}$ atmosphere. For the experiments, cells were plated in steroid-stripped medium in two-chamber slides $(2,500$ cells $\left./ \mathrm{cm}^{2}\right)$. Control cells attained confluence after 9 days of culture $\left(50,000\right.$ cells $\left./ \mathrm{cm}^{2}\right)$. Four sets of experiments were done: with estradiol (E2) $\left(10^{-9} \mathrm{M}\right)$, with hydroxytamoxifen (OH-TAM) $\left(10^{-7} \mathrm{M}\right)$, one set treated with estradiol $\left(10^{-9} \mathrm{M}\right)$ and hydroxytamoxifen $\left(10^{-7} \mathrm{M}\right)(\mathrm{E} 2 / \mathrm{OH}-\mathrm{TAM})$, and one set not treated (control). The treatments were initiated 2 days after plating and stopped $24 \mathrm{~h}$ before the immunocytochemical detection of ER. Estrogen receptor immunocytochemical assay was then performed in situ, at various times after the plating (3-9 days).

\subsection{ER enzyme immunocytochemical assay (ERICA)}

The assay was done with the Abbott kit (Chicago, IL) according to the manufacturer's instructions. Briefly, cells were seeded in two-chamber culture slides and treated as described above. Cells were fixed in paraformaldehyde at different times after the plating (3-9 days). Cells were rinsed with PBS, then permeabilized in methanol-acetone at $-20^{\circ} \mathrm{C}$. After washes in PBS, cells were reacted with $\mathrm{H} 222$ monoclonal antibody. This antibody was raised against human ER purified from MCF-7 cells and reacts with an epitope near the hormone-binding domain [16]. Cells were incubated with bridging goat anti-rat immunoglobulin G, and then with rat antiperoxidase complex. The reaction product was made visible with diaminobenzidine tetrahydrochloride and hydrogen peroxide. Cells were not counterstained so that a low level of ER could be revealed. The monoclonal antibody was omitted in processing one set of slides from each treatment; it was used as a negative control for evaluation of non specific background staining.

\subsection{Feulgen staining}

For the Feulgen-Rossenbech stoichiometric nuclear reaction [11], cells were fixed for $10 \mathrm{~min}$ in wateracetone-formaldehyde $(6: 9: 5, \mathrm{~V}: \mathrm{V})$ containing $0.02 \%$ disodium phosphate- $0.1 \%$ monopotassium phosphate, washed four times with distilled water, and air dried. Hydratation was done by immersing slides successively in $95 \%$ and $75 \%$ ethanol, then $10 \mathrm{~min}$ in water, followed by a $1 \mathrm{~h}$ hydrolysis in $6 \mathrm{~N} \mathrm{HCl}$. Cells were then rinsed four times for $1 \mathrm{~min}$ in water, 
stained for $1 \mathrm{~h}$ in Schiff reagent (Merck, Darmstad, Germany), washed four times for one minute in $0.05 \mathrm{~N}$ $\mathrm{HCl}$ containing $0.026 \mathrm{M}$ sodium bisulfite, and then for $10 \mathrm{~min}$ in running water. They were dehydrated through graded ethanols and xylene and mounted in Eukitt (Labonord).

\subsection{Image processing}

Images were recorded via the green output of a colour tri-CCD camera (JVC type) attached to an inverted microscope (IMT2 Olympus, SCOP, Rungis, France) in a SAMBA 2005 (System for Analytical Microscopy in Biological Applications) image processing environment (marketed by TITN, France). The $15 \times$ magnification was used, and four or nine contiguous $(512 \times 512)$ images were recorded in order to get enough cells for statistical significance $(\approx 1000$ for 3 days of culture to 5000 for 9 days of culture). The number of pixels per nucleus was about 170 and the pixel size was $0.631 \mu \mathrm{m}^{2}$. Images were processed on a VAX station 4000 (Digital Equipment Corporation, Nashua, NH) in the MIDAS (Munich Image Data Analysis System) environment (European Southern Observatory, Munich, Germany). We had developed a cell segmentation technique in which we used filtering algorithm (to increase the contrast between nuclei and background) and mathematical morphology (to preserve cell topography) [29,30]. In the case of ERICA, the last binary image of the segmented nuclei was used with the original density image to bring out, for each cell, its nucleus barycenter $(x, y)$ coordinates, nucleus area (surface of the nucleus projection on the $(x, y)$ plane) (A), nucleus integrated optical density (IOD). For the Feulgen-stained nuclei, 14 parameters characterising the condensation of chromatin were calculated: 6 parameters extracted from the optical density histogram, nucleus area (A), nucleus integrated optical density (IOD), mean optical density (MOD), skewness (SKE), standard deviation (SD), and kurtosis (KUR); 3 textural features calculated from the grey-level cooccurence matrix proposed by Haralick et al. [18], local mean (LM), inertia (IN), and energy (EN); and 5 calculated from the run-length section matrix proposed by Galloway [12], short-run length emphasis (SRE), long-run length emphasis (LRE), grey-level distribution (GLD), run-length distribution (RLD) and run length percentage (RLP).

\subsection{Global pattern analysis: order diagram}

Cell differentiation processes and cell-cell interactions give tissues a non random organisation. For the histopathologist the architecture expresses more or less differentiated structures. Similarly, in in vitro models, the patterns of cell proliferation are modelled by the degree of cellular interactions. Topographical analysis is able to quantitate order and disorder in biological structure in tissues [22,27] as well as in in vitro models [29]. Our approach [8-10] is based on the Minimal Spanning Tree graph (MST) constructed on the set of points representing the position of cells. The choice of the MST is supported by the comparison of different methods used to compute spatial point pattern characteristics [39]. The MST was constructed by Rohlf's algorithm $[9,34]$ as described in detail $[9,10]$. We used the coordinates of the nuclei barycenters as nodes and the Euclidian distance as edge weight. The average $m$ and the standard deviation $\sigma$ of the edge-length histogram are characteristics for the corresponding repartition [9]. To compare distributions regardless of the particle density and the sampling window, the values of $m$ and $\sigma$ must be normalised. We used the process described by Hoffman and Jain [20]. A diagram of $m$ and $\sigma$ enabled us to determine the degree of order of any distribution by taking a simple reading in the $(m$, $\sigma$ ) plane on which well characterised distributions had been located (see Fig. 2 in [29]). A dynamic analysis of the patterns of growing culture cells leads to trajectories in the $m, \sigma$ diagram reflecting the strength of their interactions $[10,29,30]$.

\subsection{Local pattern analysis: cluster detection}

The proliferation of cells in culture can result from radial development from cells initially randomly plated until confluence. Another way for cells to proliferate is for them to detach from the plate and to form new colonies in various areas of the culture until confluence. These two proliferation patterns could be associated. The MST can describe the distribution of cell clones in culture $[29,40]$. We analysed the number and the size (mean value of the number of cells) of the clones by cutting the edges larger than a given threshold $d$ in the MST built on a set of cells. The graph becomes constituted of connected components representing the so called "clusters" (see Fig. 3a in [29]). By varying the level of the threshold $d$, one can discriminate the proliferation processes. 


\subsection{Local pattern analysis: degree of relative compactness}

The MCF-7 cell line contains subpopulations more or less intermixed. To measure the intermix, we define the degree of relative compactness $[29,40]$ by counting the number of MST edges joining cells in each subpopulation and dividing by one less than the total number of MST edges. This parameter approximates the ratio of boundary to interior cells (an interior cell of a subpopulation of cells is one which is not in the vicinity of cells of the other subpopulations; a relative boundary cell is one which is in the immediate neighbourhood of some cell of the other subpopulations). We take the total number of edges minus one because the MST have at least one edge between dissimilar cells, and we want relative compactness to be 100 percent for separate subpopulations (see Fig. 3b in [29]).

\subsection{Distributions analysis}

The distributions were split into Gaussian curves. We used the Newton Raphson technique of curve fitting [13]. The Gaussians describe subpopulations of cell nuclei, and the thresholds between the subpopulations were chosen at the intersections of the Gaussians [29].

\subsection{Statistical analysis}

All data shown are representative of four separate experiments. Linear regression was used to study the correlation between Integrated Optical Density IOD, and nuclear area A at the single cell level. Statistical significance was determined using the Student $t$-test. Multifactorial discriminant analysis was used to separate several groups of Feulgen stained nuclei [21]. This analysis provides a representation on a factorial plane and give new features by linear combinations of the measured parameters. This plane should be read relative to the parameters projections and in term of distance between the different groups.

\section{Results}

\subsection{Study of MCF-7 cell proliferation}

Figure 1 shows that cell growth was dramatically stimulated by estradiol treatment. The amplitude of the stimulation rapidly reached $250 \%$ of the control level.

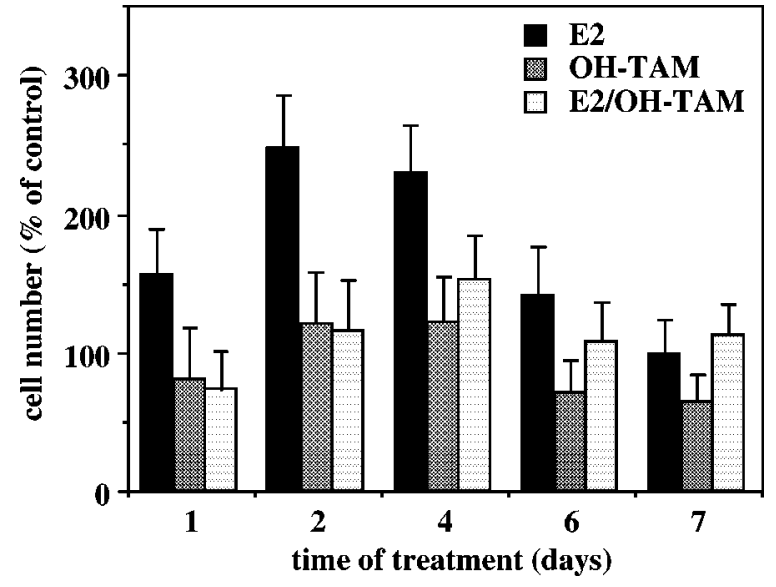

Fig. 1. Effect of treatment on MCF-7 cell proliferation. The values represent the percentage of control cells. Data are the mean and standard deviation from four sets of values.

The decrease of the relative proliferation after 4 days of treatment is due to confluency phenomena. Hydroxytamoxifen treatment induced cell growth inhibition after 6 days of treatment. The results of the double treatment showed that $\mathrm{OH}-\mathrm{TAM}$ reversed the stimulatory effect of E2.

\subsection{Heterogeneity of estrogen receptor content and nuclear size analysed by distributions}

Figure 2 illustrates the heterogeneity of the staining intensity according to the treatments at 6 days of culture. As previously described [29], the relative distributions of IOD of enzyme-immunostained ER were split into Gaussians. The Gaussians describe subpopulations of nuclei with different content of estrogen receptors. We named these subpopulations ER- (negative), ER+ (weakly positive), and ER ++ (strongly positive). The thresholds between $\mathrm{ER}-, \mathrm{ER}+$, and $\mathrm{ER}++$ subpopulations were chosen at the intersections of the Gaussians describing the populations. This process is illustrated in the lower panel of Fig. 3 on MCF7 cells before treatment. The results observed previously [29] on MCF-7 untreated cells were confirmed: when the time of culture increases the percentage of ER - cells decreases while those of both ER + and ER ++ cells increase. Likewise, Fig. 2 shows that an important parameter of MCF-7 cell heterogeneity is the size of the nuclei. The relative distributions of nuclear areas (A) for cells were also split into Gaussians as previously described [29]. The best fit was obtained for three Gaussians describing three subpopulations of nuclei that we named small areas (SA), medium areas 

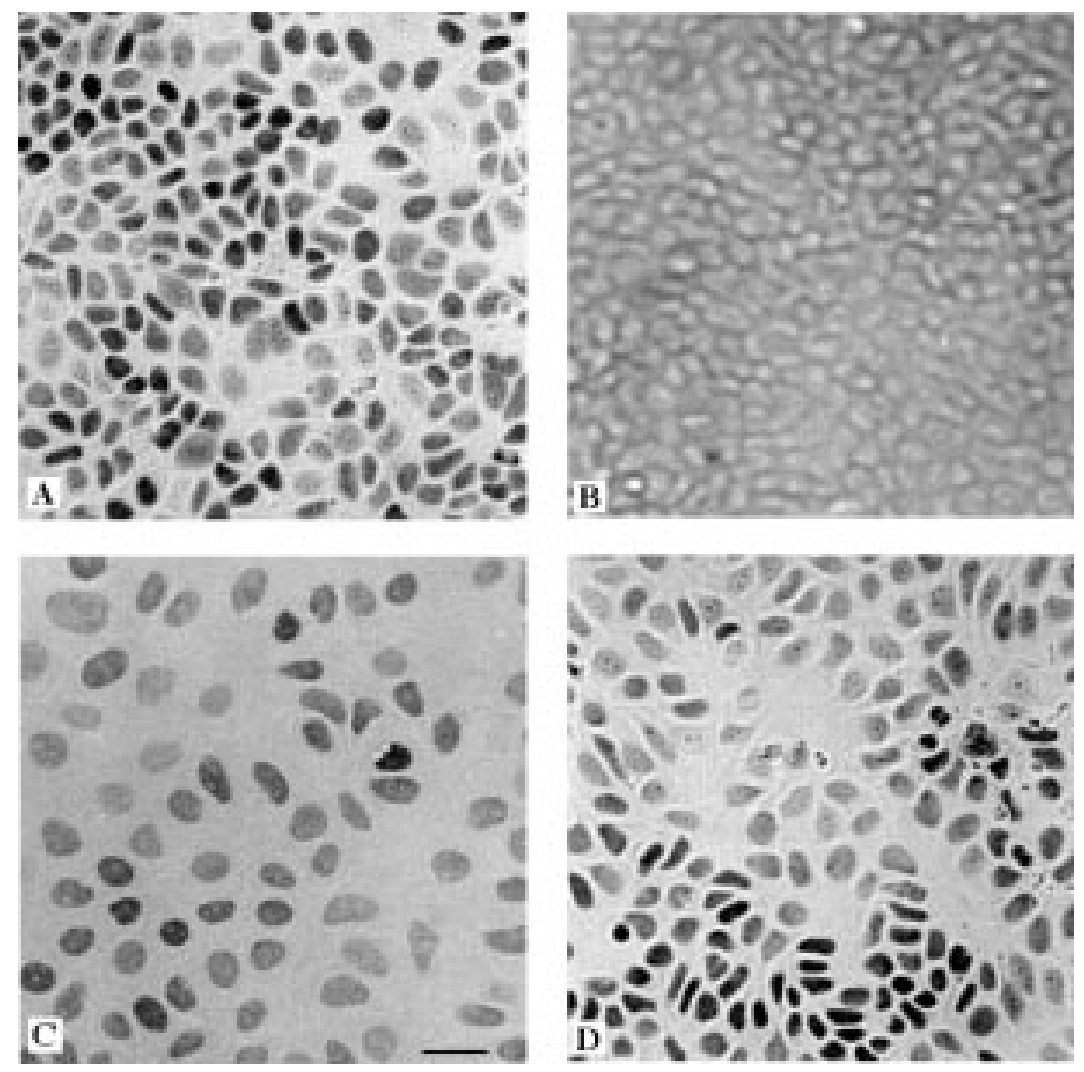

Fig. 2. Microphotographs of MCF-7 cells. A shows control cells at 8 days of culture, B, C and D show E2, OH-TAM, E2/OH-TAM treated cells after 6 days of treatment ( 8 days of culture). The bar represents $30 \mu \mathrm{m}$.

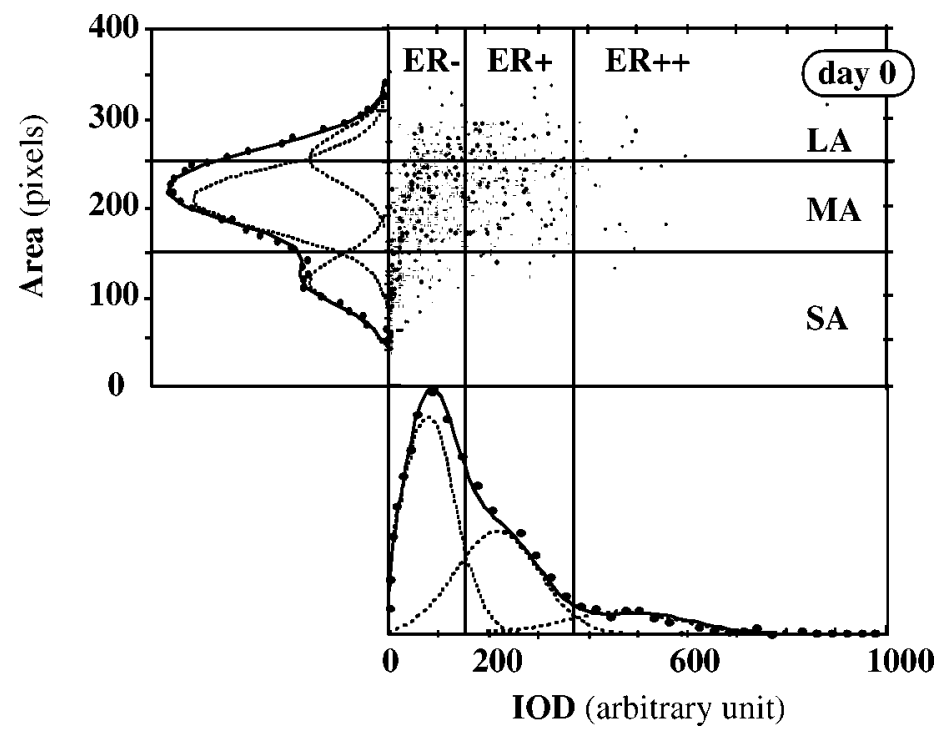

Fig. 3. Bidimensional relative plot of integrated optical density (IOD) and nuclear area (A) of MCF-7 cells at day 0 (upper right box). In the lower right box the relative distribution of IOD (dot plot) is fitted by the sum (solid curve) of three Gaussians (dashed curves) that describe the three subpopulations of nuclei with different contents of estrogen receptors $(\mathrm{ER}-, \mathrm{ER}+, \mathrm{ER}++)$. In the upper left box the relative distribution of A (dot plot) is fitted by the sum (solid curve) of three Gaussians (dashed curves) that describe the three subpopulations of nuclei with different areas (SA, MA, LA). The thresholds (Gaussians intersections) between the different subpopulations are gated in the three panels. 
(MA), and large areas (LA). The thresholds between SA, MA, and LA were chosen at the intersections of the three Gaussians describing the populations as shown in the left panel of Fig. 3. The results observed previously [29] on MCF-7 untreated cells were confirmed: when the time of culture increases the variations of the percentages of each subpopulation as function of the time of culture were slight. The upper right panel of Fig. 3 shows a representative example of the bivariate analysis of IOD and A on MCF-7 cells before treatment (day 0). Figure 4 shows representative examples of this analysis for different times of treatment. The thresholds between $\mathrm{ER}-, \mathrm{ER}+, \mathrm{ER}++, \mathrm{SA}, \mathrm{MA}$, and LA subpopulations are indicated in Fig. 4. These thresholds for the different classes are determined on untreated cultures. At the beginning of the treatments (Fig. 4A), the correlation coefficients between $\mathrm{A}$ and IOD at the single cell level ranged from 0.215 to 0.316 $(p<0.001)$ for control and treated samples, respectively. The slopes of A versus IOD for treated cells were compared to the control one by paired sample $t$-tests with no significant difference $(p>0.05)$. At 7 days of treatment (Fig. 4B), an increase in the values of the correlation coefficients of A versus IOD was observed. These values were still low for control $(0.404 \pm 0.011), \mathrm{OH}-\mathrm{TAM}$ treated $(0.522 \pm 0.026)$ and E2/OH-TAM treated $(0.339 \pm 0.034)$ samples whereas a higher value $(0.774 \pm 0.024)$ was observed for E2 treated cells $(p<0.001)$. The slopes of A versus IOD for treated cells were compared to the control one by paired sample $t$-tests. A significantly large difference was observed between control and E2 treated cells $(t=4.625, p<0.001)$. The difference between control and OH-TAM treated cells was lower $(t=1.967$, $p<0.05)$ and only minor changes $(t=0.014, \mathrm{NS})$ was obtained for E2/OH-TAM treated cells. Figure 5A shows the changes of the cell numbers in the subpopulations. A great increase in the ER- subpopulation was observed after 4 days of E2 treatment. After 7 days of antiestrogenic treatment there was a fall of $30 \%$ in the ER++ subpopulation and a rise of $200 \%$ in the ER - subpopulation. The pattern obtained by the double treatment looks like that of OH-TAM but in reduction. Figure 5B shows the variations of the cell number in each nuclear area subpopulation compared to those of control, as a function of the time of treatment. A great increase in the SA subpopulation was observed after 1 day of E2 treatment. A slump in the MA and LA subpopulations was noted after 2 days of treatment. Only after 6 days with OH-TAM treatment was there an effect on nuclear area subpopulations: a marked rise in the LA subpopulation and a decrease in the SA subpopulation. After 7 days of treatment the increase in the SA population reached $350 \%$ of control. Under the double treatment, the behaviour of the three subpopulations was similar to the control until 4 days of treatment. At this time the effect of E2 seemed to dominate temporarily, followed by a reversion of the effect of E2 by OH-TAM. Moreover we have found the variability of the results (relative subpopulation cell numbers versus time of treatment, Fig. 5) to be small versus a variation of the threshold position: less than $15 \%$ for a \pm 30 arbitrary unit shift of the IOD. This variability is of the magnitude of the internal error bars.

\subsection{Global pattern analysis: order diagram}

The treated and untreated MCF-7 cell populations were compared using MSTs. All the populations became increasingly less random as the proliferation time increased (Fig. 6). However we noted that: (i) estradioltreated cells followed a different path; they were more gradient than the others (short-term treatment) and then more ordered than the others (long-term treatment); (ii) at the same long times of culture as the other samples ( 8 and 9 days) OH-TAM treated cells remained less ordered than the others; and (iii) the distribution of E2/OH-TAM treated cells displayed a degree of order similar to the control.

\subsection{Local analysis: cluster detection}

We did MST cluster analysis on the different distributions of cells. The results obtained by cutting the edges of the MSTs larger than three different threshold values $(d)$ are shown in Table 1 . The three values of $d$ chosen were $1.5,2.0$ and 2.5 times the mean value of cell diameters $(27,40$ and $53 \mu \mathrm{m})$. At one day of $\mathrm{OH}-\mathrm{TAM}$ or E2/OH-TAM treatment, the sizes (mean value of the number of cells) of the clusters were similar to those of control. On the contrary for E2 treatment the size of the clusters were greater than those of control. The disparity between these values increased with $d$. The number of small clusters (low number of cells) is greater whereas the big clusters (great number of cells) are fewer in E2-treated cell culture. At 7 days of OH-TAM treatment, the clusters were smaller than those of untreated and E2/OH-TAM treated samples. E2-treated cells were confluent at this time. 


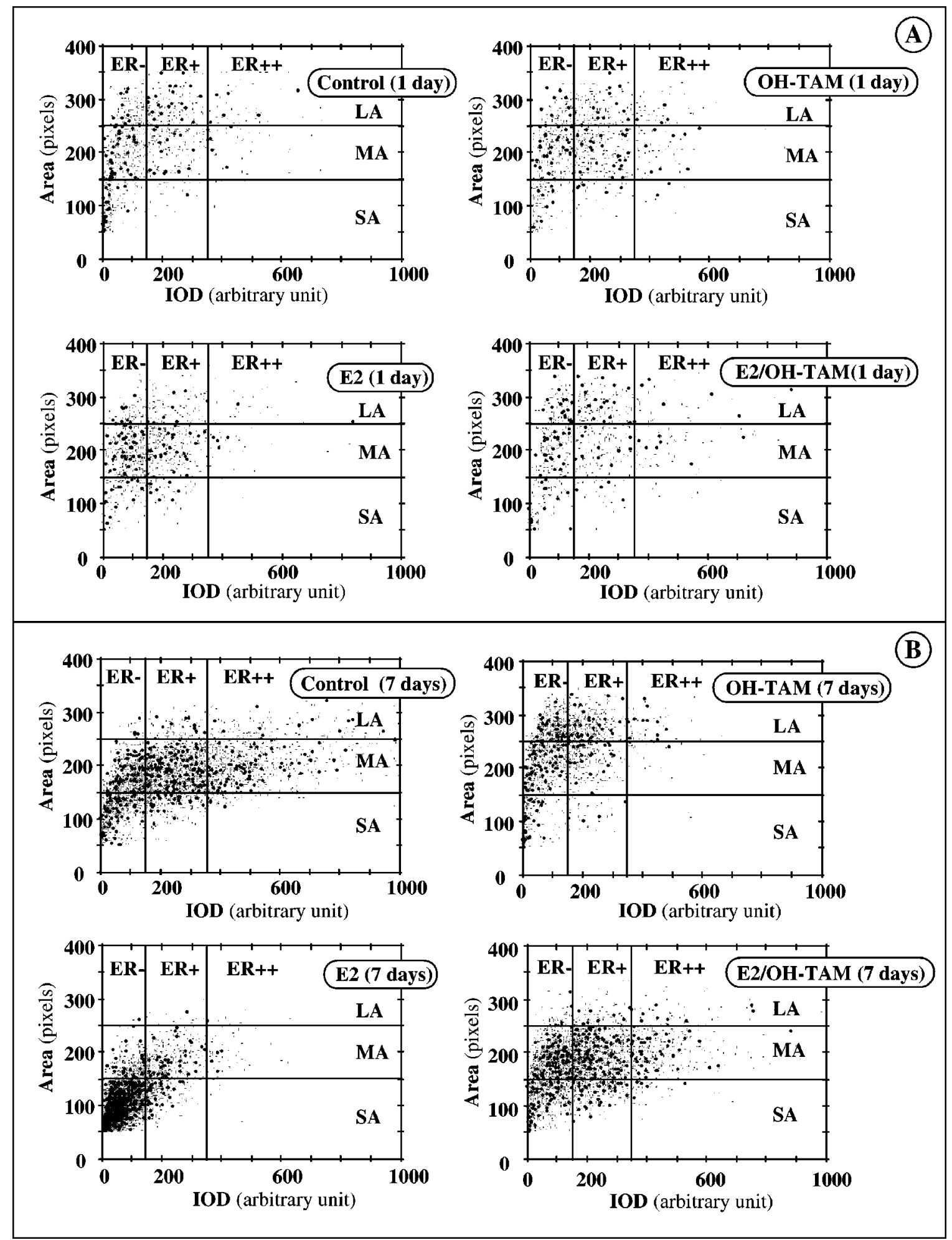

Fig. 4. Bidimensional relative plot of integrated optical density (IOD) and nuclear area (A) of MCF-7 cells. A: 1 day of treatment (3 days of culture). B: 7 days of treatment ( 9 days of culture). The thresholds between the different populations of nuclear size and nuclear estrogen receptor content are gated. 


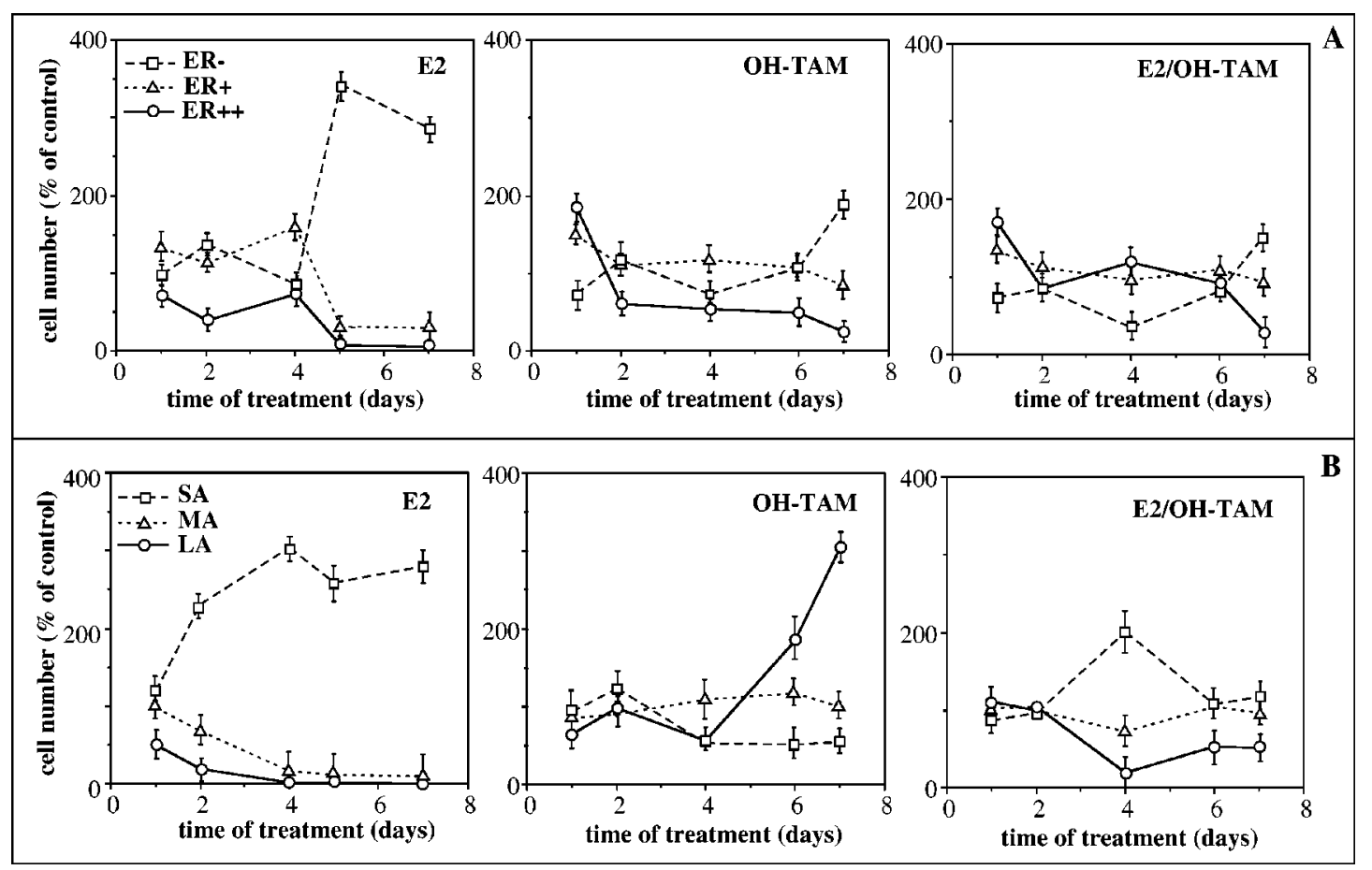

Fig. 5. A: Variations of the number of the three subpopulations ER-, ER+, ER++ relative to control, versus the time of treatment. B: Variations of the number of the three subpopulations SA, MA, LA relative to the control, versus the time of treatment. Data are the mean \pm SD from four independent experiments.

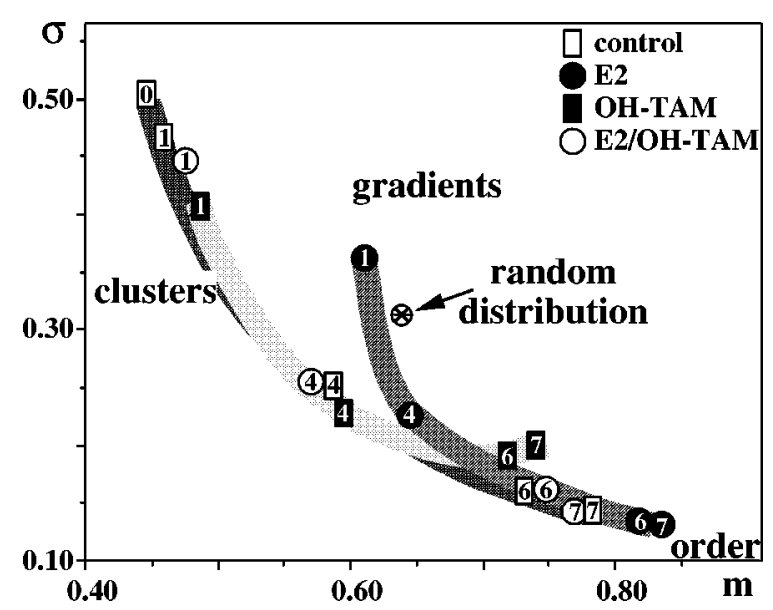

Fig. 6. The $(m, \sigma)$ plane. The star $(\star)$ pertains to a perfectly random distribution. If the mean of the experimental results, $m$, is below that of a random distribution, this is indicative of a tendency to cell clustering. If the value of the standard deviation $\sigma$ is above that of the random distribution there is a trend toward gradient formation. Organised distributions are characterised by small values of $\sigma$. The $(\square)$ pertain to control cells, $(\boldsymbol{Q}, \mathbf{\square}$ and $\bigcirc)$ pertain respectively to E2, OH-TAM and E2/OH-TAM treated cells. The duration of the treatments are indicated in the symbols.

\subsection{Local analysis: degree of relative compactness}

We computed the values of the relative compactness for the three subpopulations of estrogen receptor content $(\mathrm{ER}-, \mathrm{ER}+, \mathrm{ER}++)$ and the three subpopulations of nuclear area (SA, MA, LA). As observed previously [29], the relative compactness of control cells as a function of nuclear estrogen receptor decreases at the beginning of the proliferative process and then remains constant. On comparing these values to those of the treated cells (Fig. 7A), the intermix (inverse of compactness) of the three ER-populations under OH-TAM or E2/OH-TAM was first slightly greater, then similar, finally slightly lower. Inversely, the intermix of the subpopulations treated by E2 was always lower than the control one. As observed previously, in the case of untreated control cells the values of the relative compactness for the three subpopulations of nuclear area [29] increase as a function of the culture time. On comparing these values to those of the treated cells (Fig. 7B), the intermix of the three classes was slightly greater when the cells were treated by OH-TAM and dramatically lower for the E2 treatment. Short term E2/OHTAM treatment led to values similar to that measured for E2-treated cells whereas long-term treatment al- 
Table 1

Results of the cluster analysis on the different treated samples ${ }^{\mathrm{a}}$

\begin{tabular}{|c|c|c|c|}
\hline Threshold: $d(\mu \mathrm{m})$ & 27 & 40 & 53 \\
\hline \multicolumn{4}{|l|}{ Control (1 day) } \\
\hline mean cluster size ${ }^{b}$ & $1.5 \pm 0.1$ & $5.0 \pm 0.5$ & $12.8 \pm 2.8$ \\
\hline number of clusters ${ }^{c}$ & $358 \pm 10$ & $101 \pm 8$ & $50 \pm 7$ \\
\hline \multicolumn{4}{|l|}{ E2 treatment (1 day) } \\
\hline mean cluster size ${ }^{b}$ & $2.6 \pm 0.3$ & $42.6 \pm 0.9$ & $142.1 \pm 9.7$ \\
\hline number of clusters ${ }^{c}$ & $487 \pm 12$ & $32 \pm 6$ & $7 \pm 2$ \\
\hline \multicolumn{4}{|c|}{ OH-TAM treatment ( 1 day) } \\
\hline mean cluster size ${ }^{b}$ & $1.6 \pm 0.1$ & $8.4 \pm 0.5$ & $19.2 \pm 0.9$ \\
\hline number of clusters ${ }^{\mathrm{c}}$ & $291 \pm 18$ & $58 \pm 5$ & $20 \pm 15$ \\
\hline \multicolumn{4}{|c|}{ E2/OH-TAM treatment (1 day) } \\
\hline mean cluster size $\mathrm{e}^{\mathrm{b}}$ & $1.5 \pm 0.1$ & $5.4 \pm 0.8$ & $13.9 \pm 1.7$ \\
\hline number of clusters ${ }^{\mathrm{c}}$ & $263 \pm 15$ & $76 \pm 5$ & $31 \pm 4$ \\
\hline \multicolumn{4}{|l|}{ Control (7 days) } \\
\hline mean cluster size $\mathrm{e}^{\mathrm{b}}$ & $2.3 \pm 1.0$ & $22.3 \pm 9.6$ & $170 \pm 11.5$ \\
\hline number of clusters ${ }^{c}$ & $579 \pm 15$ & $79 \pm 12$ & $13 \pm 5$ \\
\hline \multicolumn{4}{|c|}{ OH-TAM treatment (7 days) } \\
\hline mean cluster size $\mathrm{e}^{\mathrm{b}}$ & $1.3 \pm 0.05$ & $5.2 \pm 0.7$ & $30.5 \pm 9.6$ \\
\hline number of clusters ${ }^{\mathrm{c}}$ & $652 \pm 14$ & $166 \pm 10$ & $27 \pm 7$ \\
\hline \multicolumn{4}{|c|}{ E2/OH-TAM treatment (7 days) } \\
\hline mean cluster size $\mathrm{b}^{\mathrm{b}}$ & $2.0 \pm 0.2$ & $33.5 \pm 7.8$ & $333.5 \pm 30.0$ \\
\hline number of clusters ${ }^{c}$ & $723 \pm 7$ & $49 \pm 8$ & $6 \pm 4$ \\
\hline
\end{tabular}

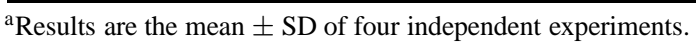

${ }^{\mathrm{b}}$ Number of cells.

${ }^{\mathrm{c}}$ Reported to the same area in every population.

lowed to an intermix comparable to that observed in $\mathrm{OH}-\mathrm{TAM}$ cell cultures.

\subsection{Cytomorphonuclear analysis on Feulgen-stained nuclei}

Feulgen-stained nuclei provide quantitative morphological information on nuclear size, DNA content, and chromatin pattern. Multifactorial discriminant analysis on the 14 parameters measured on each Feulgenstained cell was used to separate classes corresponding to the treated or untreated cells at each time of treatment. In a first step four groups, one control and the three treatments were analysed (Fig. 8). From the start of the treatment, the pattern of E2 treated group is well separated from the control one, whereas $\mathrm{OH}$ TAM treated one become distinguishable from control only after 6 days of treatment. The projections of the 14 parameters in the principal plane (on the right hand of Fig. 8) show that the most discriminant parameters are those extracted from the optical density histogram and those calculated from the run-length section matrix. To refine the analysis, nine groups were considered corresponding to the three area subpopulations (SA, MA, LA) for control, E2 and OH-TAM treatments. As shown in Fig. 9 the nuclear surface A and the parameters extracted from the run-length matrix contribute to the discrimination between area subpopulations while parameters calculated from the optical density histogram contribute to the discrimination between control and treated cells.

\section{Discussion}

Recently, Levenson and Jordan [24] published an article paying tribute to Dr Soule, the scientist who developed the MCF-7 breast cancer cell line. Those authors reviewed the main advances in the field of hormone regulated cell replication and endocrine therapy of breast cancer during the last twenty-five years, through the history of the research with this cell line. As described by Levenson and Jordan, the MCF-7 cell line has become a standard model: "the first hormone responsive breast cancer cell line". Nevertheless, the heterogeneity of this cell line is rarely considered, al- 

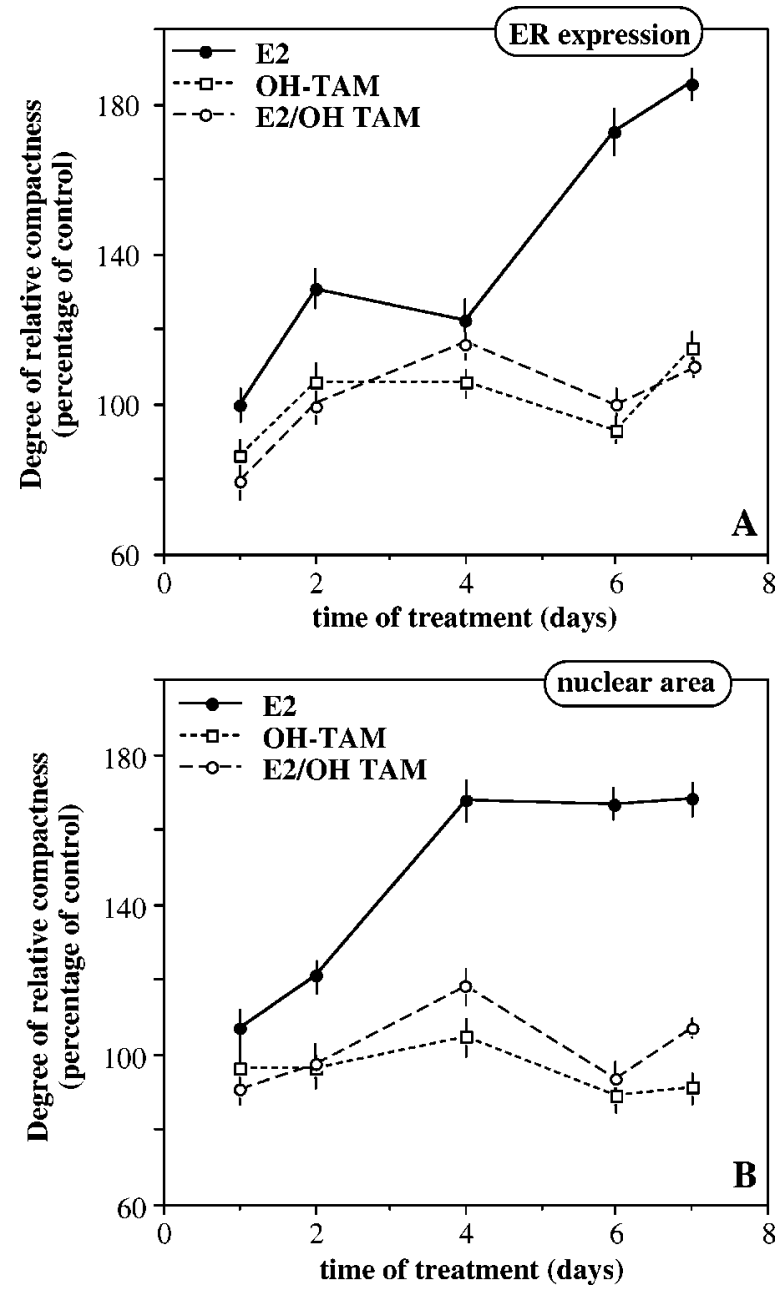

Fig. 7. Degree of relative compactness of MCF-7 cells as a function of nuclear estrogen receptor content (A) and nuclear area (B). Data are the mean $\pm \mathrm{SD}$ from four independent experiments.

though it has been described by several groups [29,33]. Thus the importance of evaluating steroid receptor heterogeneity by image analysis in breast cancer has been recognised [2,4,26,36].

We developed a quantitative image analysis method [29] allowing, in a first step, the detection and the description of cell subpopulations and, in a second step, the characterisation of the topographical evolution of these subpopulations in their growing phase. We previously exhibited the heterogeneity of the MCF-7 cell line representative of hormone responsive breast cancer, in terms of nuclear size and estrogen receptor (ER) content [29]. We demonstrated that the repartition of the cell subpopulations is not random and that the development of these cell subpopulations as a function of culture time is associated with an increase in ER level that could occur through phenotypic alterations. In the present study we applied our technology to growing MCF-7 cells under estradiol or/and hydroxytamoxifen treatments.

Cell growth is dramatically stimulated by E2 treatment. This stimulation goes with a remodeling of the subpopulations distribution. From the start of the treatment, cell populations with small nuclei are stimulated. One explanation of these changes could be the modifications of the partitions of the cells in the cell cycle. Indeed we showed [38] that after one day of estradiol treatment there was an increase in the relative number of MCF-7 cells in G2/M phases (about $200 \%$ ) with a concomitant decrease in G0/G1. But the size modifications of the nuclei could not been explained by these cycle variations since G2/M cells should have large nuclei. Modifications of the pattern of chromatin (Fig. 8) that arise from the start of the treatment plead in favour of direct phenotypic changes in the proliferative responsive subpopulation. Similar changes with rearrangement of keratin filaments was found by Sapino et al. [35] for MCF-7 cells treated by E2. The chromatin condensation is induced by E2 simultaneously on the three SA, MA and LA subpopulations which remain different according to surface and texture parameters (Fig. 9). After 5 days of treatment, the pattern of A versus IOD in immunocytochemical assay is significantly different from this of control. The increase of the values of the correlation coefficient of A versus IOD with the time of treatment and the evolution of the percentage of cells in the different subpopulations show that only one subpopulation remains, the SA ER - subpopulation. Since ER is principally expressed during the G1 phase of the cycle in MCF-7 cell line [7,17], the negativity of ER expression after 5 days of treatment could be partly explained by the position of the cells in the cell cycle: decrease of $50 \%$ of the relative number of cells in the G0/G1 phases at this time [38]. This phase shift involves that the measured stimulation of cell growth occurs through a recruitment of G0 phase cells into proliferation and a speed up of G1 phase. Note that the modifications in the expression of receptors occur suddenly after 5 days of treatment even though modifications in size, pattern of chromatin (Fig. 7), and in the percentage number of cells in the cell cycle start from the first day of treatment. Also, the change in ER status may be induced by diffusible factors. This hypothesis is supported by the observation that conditioned medium produced by high cell density culture induces a stimulation of ER expression in MCF-7 cells [29]. Another hypothesis could be that 

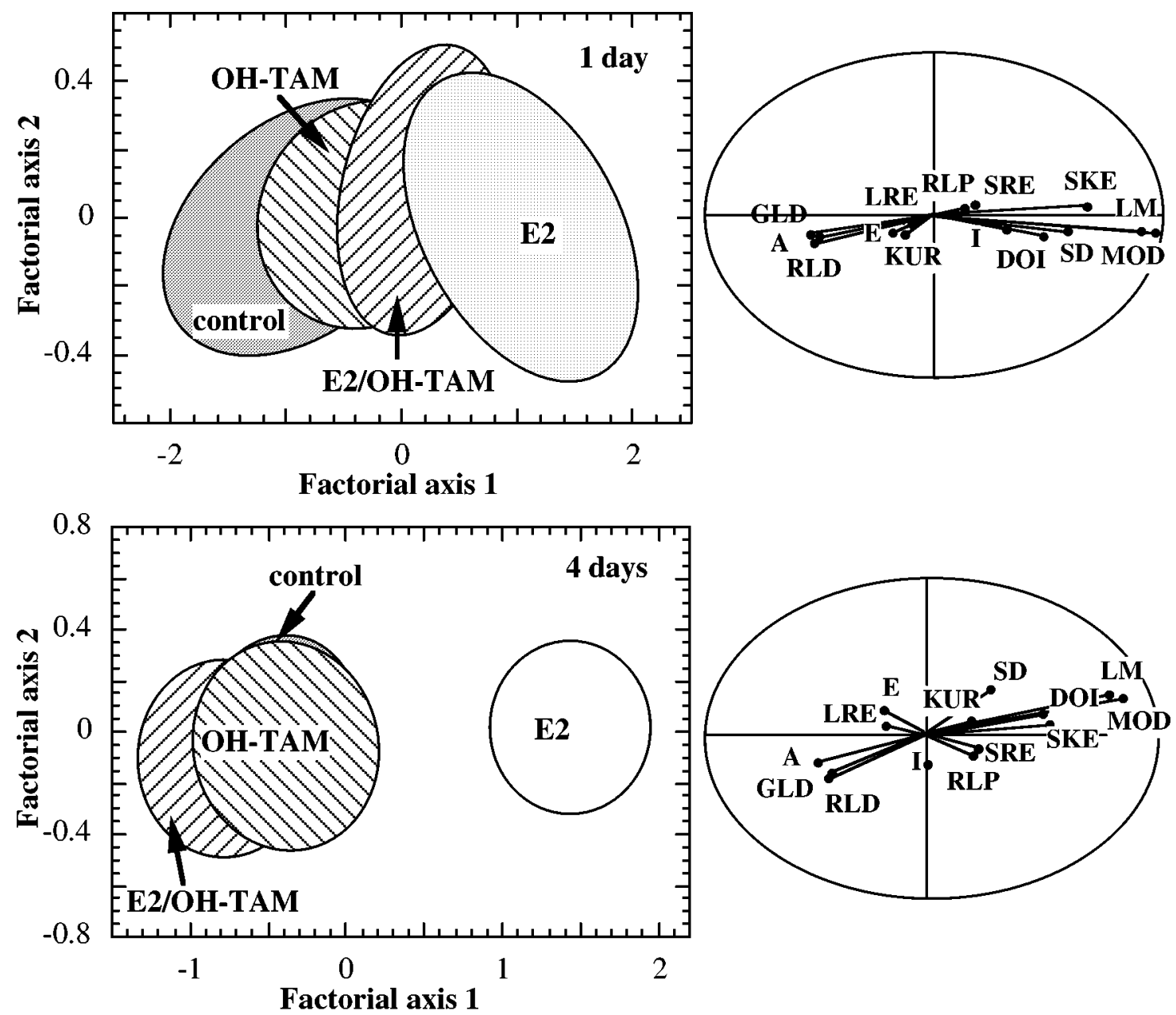

Factorial axis 1

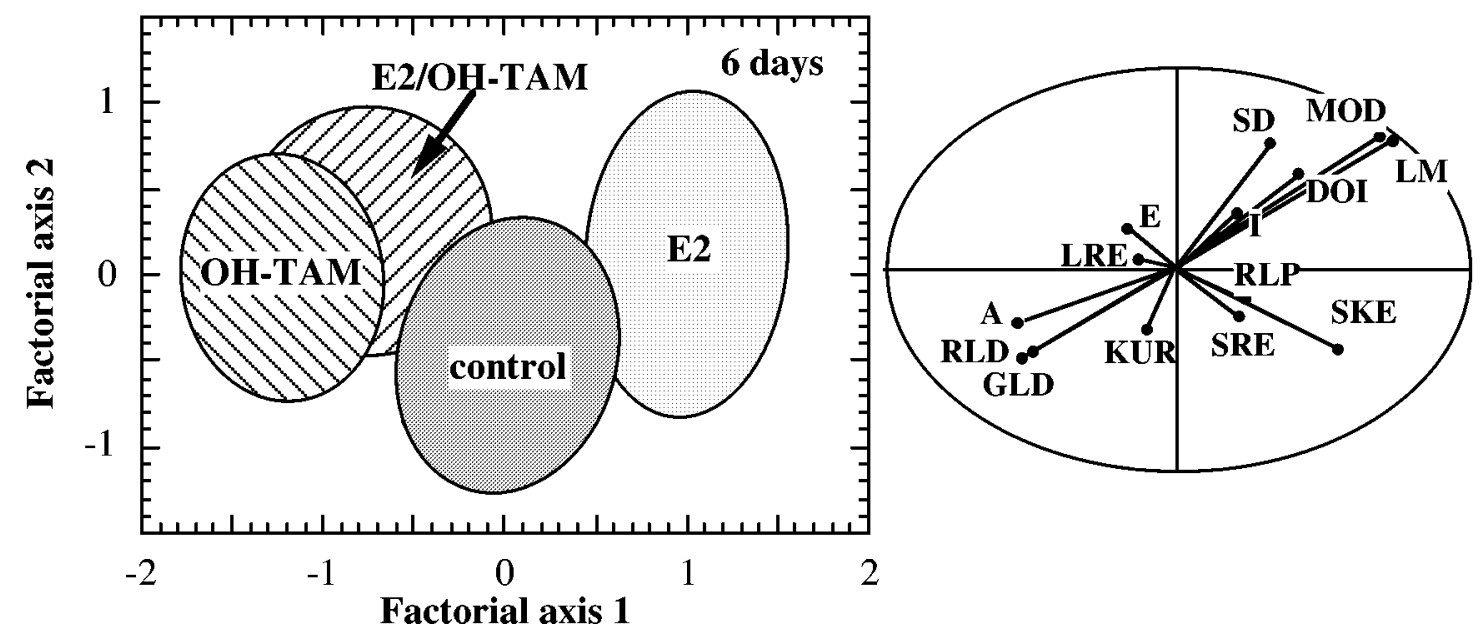

Fig. 8. Scattergram of the treated and untreated cells in the factorial principal plane determined by the multifactorial discriminant analysis on the Feulgen-stained nuclei. Each axis is a linear combination of the 14 axes related to the 14 parameters computed for each nucleus. Four groups were analysed control, E2, OH-TAM and E2/OH-TAM treated cells for different times of treatments. Left hand: ellipses delineate the 95\% tolerance region around the center of gravity of each group. Right hand: projections of the 14 parameters. 


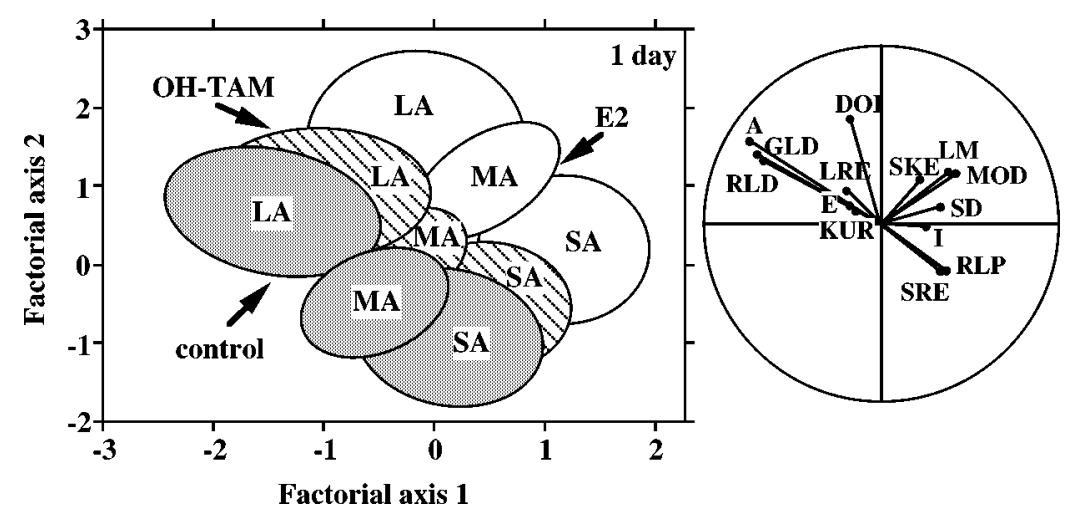

Fig. 9. Scattergram of the treated and untreated cells in the factorial principal plane determined by the multifactorial discriminant analysis on the Feulgen-stained nuclei. Each axis is a linear combination of the 14 axes related to the 14 parameters computed for each nucleus. Nine groups were considered, the three area subpopulations (SA, MA and LA) for control, E2 and OH-TAM treatments. Left hand: ellipses delineate the 95\% tolerance region around the center of gravity of each group. Right hand: projections of the 14 parameters.

the number of receptors at the end of the treatment falls below the limits of detection of the method. In the same way, normal human mammary epithelial cells respond to estradiol in the absence of detectable estrogen receptor [4,5,14]. Recently [25] a second form of $\mathrm{ER}, \mathrm{ER}-\beta$ in both normal and neoplastic human mammary tissues has been evidenced. As the immunocytochemical assay we used only detects the isoform $\alpha$ of ER, the hypothesis of the presence of undetectable ER- $\beta$ in the cells should not be dismissed. Thus, the loss of ER expression concomitant with the confluency of the cells should require a threshold of sensitivity or result from contact factors. The homogeneity of the cell line under estradiol treatment is confirmed by the spatial organisation of the cells (Fig. 6). The global analysis $(m, \sigma$ plane $)$ confirms the earliness of the drug effect. The cluster analysis displays two phenomena: (i) an increase in the number of the smallest clusters (containing slightly more cells than the control ones) and (ii) the appearance of very few large clusters for the higher value of the threshold pointing out percolation phenomena. These results and the great increase in the relative compactness of cells support a scenario in which estradiol largely modifies the phenotype of the proliferative subpopulation and stimulates its proliferation. That proliferation in situ occurs simultaneously with the appearance of a many new colonies in various areas of the culture suggesting that estradiol induces permissive proliferation for the selected subpopulation of SA cells.

Cell growth is slightly inhibited by OH-TAM after 6 days of treatment. The increase in the correlation coefficient of A versus IOD with the time of treatment, significantly greater than the values obtained for con- trol, and the percentage number analysis of Fig. 5 show that the heterogeneity of the treated cells is reduced. After 6 days of treatment LA ER- and LA ER+ subpopulations predominate. Since we showed [38] that at this time there is a slight increase in G0/G1 cells (about $125 \%$ of control) and since ER are expressed principally in this phase [7], an increase in the ER expression should be expected. Yet the contrary is found. The large size of the nuclei could be only partly explained by the cell cycle variations (an increase of $250 \%$ of LA cells whereas the increase in G0/G1 is only $125 \%$ of the control cells). Thus under OH-TAM treatment the responsive population disappears for the benefit of subpopulations that are phenotypically ER negative or poorly positive with large nuclei. Because the effect of $\mathrm{OH}$-TAM is late it could be induced by contact factors. A slight disorganisation of the spatial distribution of all the cells in the culture is observed at the end of the treatment. The cluster analysis simultaneously shows a decrease in the mean number of cells in clusters, and this decrease rises with the greater threshold of the MST. These local properties could be partly explained by the increase in the size of the nuclei and partly by a decrease in the intracellular strengths induced by the antihormonal treatment. The reorganisation of the subpopulations does not give rise to a great increase in the relative compactness, contrarily to E2 treatment. Since the heterogeneity of the cell line is decreased by the treatment, these results show that the cells in the minority subpopulations are scattered through the cells in the majority subpopulation. We therefore propose that the decreased heterogeneity of the cell line arises by the selection of a hydroxytamoxifen unresponsive subpopulation which should give rise in the long term to 


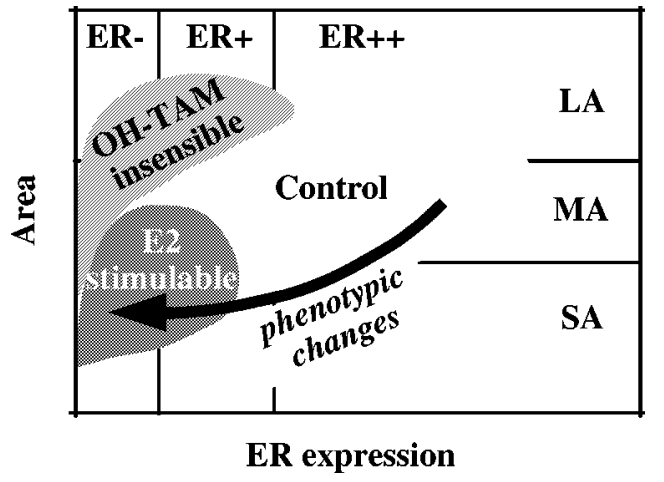

Fig. 10. Diagram showing the remodeling of MCF-7 cell subpopulations under estrogenic (E2) and antiestrogenic (OH-TAM) treatment.

hydroxytamoxifen-resistant cell lines such as MCF-7 LY2, MCF-7 LCC1 and MCF-7 LCC2 [24]. It would be interesting to analyse the pattern of morphology as well as the degree of organisation of these cell lines.

Morphological and topographical analysis of the dynamical evolution of a growing MCF-7 cell line indicates two mechanisms of subpopulation selection by estrogen and antiestrogen: estradiol acts by very rapidly changing phenotypes of the whole population, transforming them into SA ER-, whereas OH-TAM acts by selective pressure, inhibiting the growth of most of the subpopulations, leaving untouched the LA ER- one (Fig. 10).

The effect of estrogenic treatment is reversed by the antiestrogenic treatment especially in the long term. This reversal is seen on the statistical analysis of A versus IOD, on the subpopulation numbers and on the topographical behaviour of these subpopulations. The heterogeneity of the cell line is maintained by the simultaneous action of the hormone and the antihormone. This maintenance emphasises the role played by the different subpopulations on each other since the lack of some of them leads to differential proliferation processes.

The changes in cancer cells that lead to development of hormone resistance constitute a major problem in tumour biology $[1,23]$. Many mechanisms have been invoked to explain the emergence of hormone resistant tumours [23]: (i) loss of ER; (ii) alteration in ER structure; (iii) changes in paracrine interactions; (iv) abnormal metabolism of tamoxifen; (v) overexpression of growth factors. These mechanisms generally presuppose an underlying cellular uniformity. Our results on the hormone responsive MCF-7 cell line widely used to study hormone action in culture, suggest that, under the influence of hormone or antihormone, breast tumours become similarly remodelled and that selected subpopulations are affected by the drugs (Fig. 10). Such a remodeling of the heterogeneity of a cell line under antihormone treatment was reported by Graham II et al. using flow cytometry [15]. The understanding of individual interaction mechanisms is not sufficient to explain the collective behaviour of the cells and the characterisation of the cellular organisation give an advantage in order to have a better understanding of these interactions. With our assay the combination of cell count, cytomorphological parameters, and patterns of cell organisation revealed the magnitude of the potential of structuration of hormones or antihormones on in vitro growing cells. While it must be kept in mind that cancer development in vivo is very complex and not equivalent to a monolayer of epithelial cells growing on a slide, these models may be useful to study the autocrine and paracrine interactions between the different subpopulations representative of the epithelial compartment of solid tumours. It seems that the only quantification of ER in breast tumours is not sufficient as prognostic marker for antiestrogen therapy and that it should be important to take the pattern of cellular heterogeneity into account.

\section{Acknowledgements}

We thank the following for technical assistance during this study: J. Carbone (cell cultures), H. Gerard (Feulgen staining).

\section{References}

[1] M. Bilimoria and V.C. Jordan, The duration of adjuvant tamoxifen therapy, in: Biological and Hormonal Therapies of Cancer, K.A. Foon and H.B. Muss, eds, Kluwer Academic Publishers, Boston, 1998, pp. 181-192.

[2] C. Charpin, P.M. Martin, B. De Victor, M.N. Lavaut, M.C. Habib, I. Andrac and M. Toga, Multiparametric study (SAMBA 200) of estrogen receptor immunocytochemical assay in 400 human breast carcinomas: Analyis of estrogen receptor distribution heterogeneity in tissues and correlations with dextran charcoal assays and morphological data, Cancer Res. 48 (1988), 1578-1586.

[3] D. Coffey, Self-organisation, complexity and chaos: the new biology for medecine, Nature Medecine 4 (1998), 882-885.

[4] O. Cohen, G. Brugal, D. Seigneurin and J. Demongeot, Image cytometry of estrogen receptors in breast carcinomas, Cytometry 9 (1988), 579-587.

[5] E. Colomb, P. Berthon, C. Dussert, F. Calvo and P.M. Martin, Estradiol and EGF requirements for cell cycle progression of normal human mammary epithelial cells in culture, Int. J. Cancer 49 (1991), 932-937. 
[6] P.D. Darbre and R.J. King, Progression to steroid insensitivity can occur irrespective of the presebce of functional steroid receptors, Cell 51 (1987), 521-528.

[7] X.F. Dong, Y. Berthois, E. Colomb and P.M. Martin, Cell cycle phase dependence of estrogen and epidermial growth factor (EGF) receptor expression in MCF-7 cells: implications in antiestrogen and EGF cell responsivness, Endocrinology 129 (1991), 2719-2728.

[8] C. Dussert, F. Kopp, P. Gandilhon, N. Pourreau-Schneider, M. Rasigni, J. Palmari, G. Rasigni, P.M. Martin and A. Llebaria, Toward a new approach in tumor cell heterogeneity studies using the concept of order, Anal. Cell. Pathol. 1 (1989), 123-132.

[9] C. Dussert, G. Rasigni, M. Rasigni, J. Palmari and A. Llebaria, Minimal spanning tree: a new approach for studying order and disorder, Phys. Rev. B34 (1986), 3528-3531.

[10] C. Dussert, M. Rasigni, J. Palmari, G. Rasigni, A. Llebaria and F. Marty, Minimal spanning tree analysis of biological structures, J. Theor. Biol. 125 (1987), 317-323.

[11] R. Feulgen and H. Rossenbech, Mikrosckopich chemischer nachweis einer nucleisaüre und die darauf hesuhende elektive färbung von zelkernen in mikroskopischen prä paraten, Zschr. Physiol. Chem. 135 (1924), 203-248.

[12] M.M. Galloway, Texture analysis using gray level run lengths, Comput. Graph. Imag. Process. 4 (1975), 172-179.

[13] P.E. Gill, W. Murray and M.H. Wright, Practical Optimization, Academic Press, London, 1981.

[14] M.L. Graham II, P.A. Bunn, P.B. Jewett, C. Gonzalez-Aller and K.B. Horwitz, Simultaneous measurment of progesterone receptors and DNA indices by flow cytometry: characterization of an assay in breast cancer cell line, Cancer Res. 49 (1989), 3934-3942.

[15] M.L. Graham II, J.A. Smith, P.B. Jewett and K.B. Horwitz, Heterogeneity of progesterone receptor content and remodeling by tamoxifen characterize subpopulations of cultured human breast cancer cells: Analysis by quantitative dual parameter flow cytometry, Cancer Res. 52 (1992), 593-602.

[16] G.L. Greene, N.B. Sobel, W.J. King and E.V. Jensen, Immunochemical studies of estrogen receptors, J. Steroid. Biochem. 20 (1984), 51-56.

[17] J.T. Hamm and J.C. Allegra, Loss of hormonal responsiveness, in: Endocrine Management of Cancer, B.A. Stoll, ed., Karger Press, Basel, 1988, pp. 61-71.

[18] R.M. Haralick, K. Shanmugan and I. Dinstein, Textural feature for image classification, IEEE T. Syst. Man. Cyb. SMC-3 (1973), 610-621.

[19] G.H. Heppner, Tumor heterogeneity, Cancer Res. 44 (1984), 2259-2265

[20] R. Hoffman and A.K. Jain, A test of randomness based on the minimal spanning tree, Pattern Recognition Letters 1 (1983), 175-180.

[21] H. Hotteling, Analysis of a complex of statistical variables into principal components, J. Educ. Psych. 24 (1933), 417-441, 498-520.

[22] K. Kayser, H. Stute and M. Tacke, Minimum spanning tree, integrated optical density and lymph node metastasis in bronchial carcinoma, Anal. Cell. Pathol. 5 (1993), 225-234.
[23] G. Kimmick and H. Muss, Endocrine therapy in metastatic breast cancer, in: Biological and Hormonal Therapies of Cancer, K.A. Foon and H.B. Muss, eds, Kluwer Academic Publishers, Boston, 1988, pp. 231-253.

[24] A.S. Levenson and V.C. Jordan, MCF-7: The first hormoneresponsive breast cancer cell line, Cancer Res. 57 (1997), 3071-3078.

[25] E. Leygue, H. Dotzlaw, P. Watson and L. Murphy, Altered raceptor $\alpha$ et $\beta$ messenger RNA expression during human breast tumorigenesis, Cancer Res. 58 (1998), 3197-3201.

[26] A. Maiorana, V. Cavallari, A. Bagni, A.F. Ussia, M.C. Maiorana and R.A. Fano, Nuclear areas in breast cancer: relationship with estrogen and progesterone receptor expression, Anal. Cell. Pathol. 11 (1996), 199-209.

[27] G.A. Meijer, S.G.M. Meuwissen and J.P.A. Baak, Classification of colorectal adenomas with quantitative pathology. Evaluation of morphometry, stereology, mitotic counts and syntactic structure analysis, Anal. Cell. Pathol. 9 (1995), 311-323.

[28] W.R. Miller, Endocrine treatment for breast cancers: Biological rationale and current progress, J. Steroid. Biochem. Mol. Biol. 37 (1990), 167-180

[29] J. Palmari, C. Dussert, Y. Berthois, C. Penel and P.M. Martin, Distribution of estrogen receptor heterogeneity in growing MCF-7 cells measured by quantitative microscopy, Cytometry 27 (1997), 26-35.

[30] J. Palmari, N. Teysseire, C. Dussert and D. Raoult, Image cytometry and topographical analysis of proliferation of endothelial cells in vitro during Bartonella (Rochalimaea) infection, Anal. Cell. Pathol. 11 (1996), 13-30.

[31] L.P. Pertschuk, K.B. Eisenberg, A.C. Carter and J.G. Feldman, Heterogeneity of estrogen binding sites in breast cancer; morphologic demonstration of relationship to endocrine response, Breast Cancer Res. Treat. 5 (1985), 137-147.

[32] J. P. Raynaud and T. Ojasoo, The design and use of sex steroid antagonists, J. Steroid Biochem. 25 (1986), 811-833.

[33] M. Resnicoff, E.E. Medrano, O.I. Podhajcer, A.I. Bravo, L. Bover and L. Mordoh, Subpopulations of MCF-7 cells separated by Percoll gradient centrifugation: A model to analyse the heterogeneity of human breast cancer, Proc. Natl. Acad. Sci. USA 84 (1987), 44-48.

[34] F.J. Rohlf, A probabilistic minimum spanning tree algorithm, Inf. Process. Lett. 7 (1978), 44-48.

[35] A. Sapino, F. Pietribiasi, G. Bussolati and P.C. Marchisio, Estrogen- and Tamoxifen-induced rearrangement of cytoskeletal and adhesion structures in breast cancer MCF-7 cells, Cancer Res. 46 (1986), 2526-2531.

[36] R.J. Sklarew, R. Wali, M. Auger, L.D. Kidd and R.L. Katz, Estrogen receptor immunostaining patterns imaged in breast cancer fine needle aspirates, Anal. Quant. Cytol. Histol. 16 (1994), 293-305.

[37] H.D. Soule, J. Vasquez, A. Long, S. Albert and M. Brennan, A human cell line from a pleural effusion derived from a breast carcinoma, J. Natl. Cancer Inst. 51 (1973), 1409-1416.

[38] F. Wallet, Y. Berthois, P.M. Martin, C. Dussert and J. Palmari, Apport de l'analyse topographique à la microscopie quantitative dans l'étude des systèmes cellulaires en culture: application à l'évaluation des traitements hormonaux, Bull. Cancer 6 (1997), 589-595. 
[39] F. Wallet and C. Dussert, Multifactorial comparative study of spatial point pattern analysis methods, J. Theor. Biol. 3016 (1997), 437-457.
[40] C.T. Zahn, Graph-theoretical methods for detecting and describing gestalt clusters, IEEE Trans. Comp. c-20 (1971), 6886. 


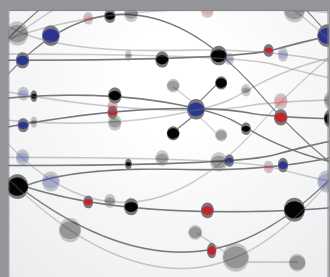

The Scientific World Journal
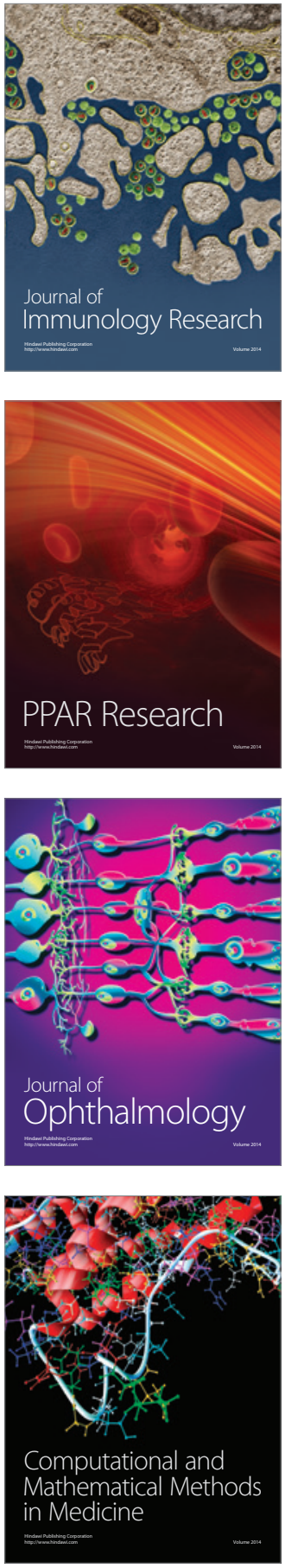

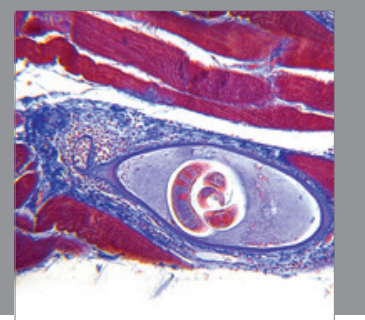

Gastroenterology

Research and Practice
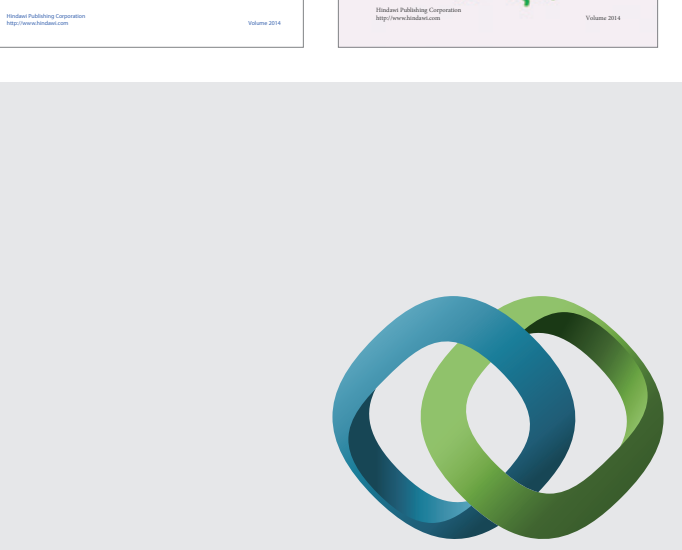

\section{Hindawi}

Submit your manuscripts at

http://www.hindawi.com
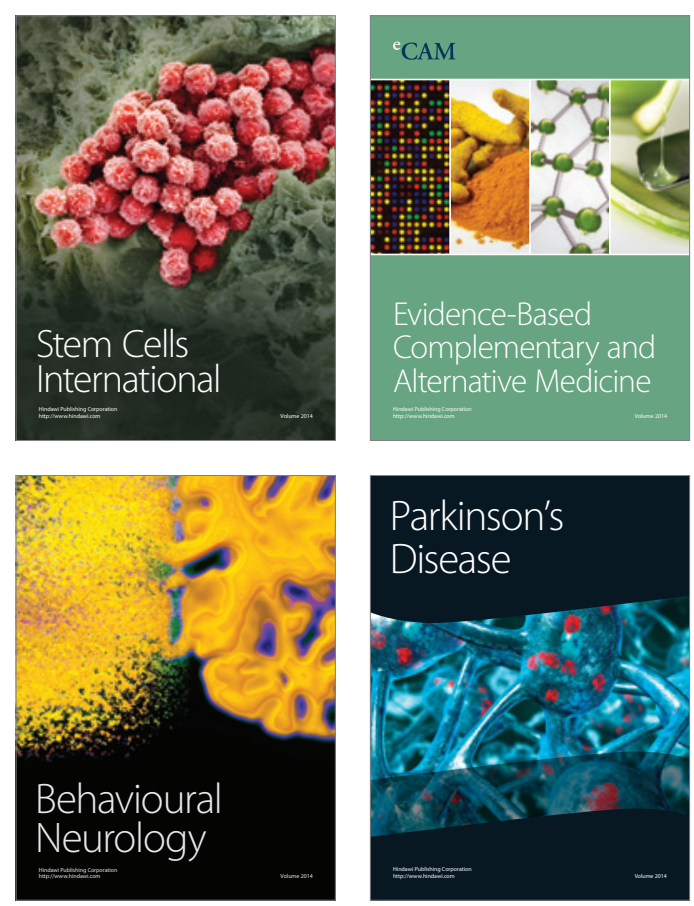

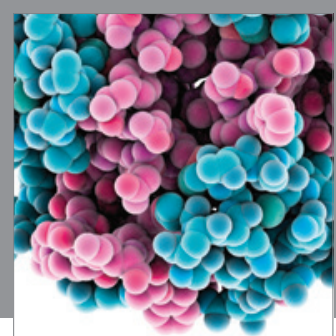

Journal of
Diabetes Research

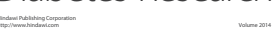

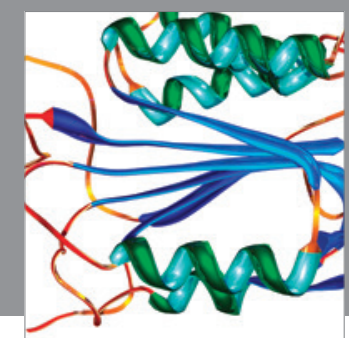

Disease Markers
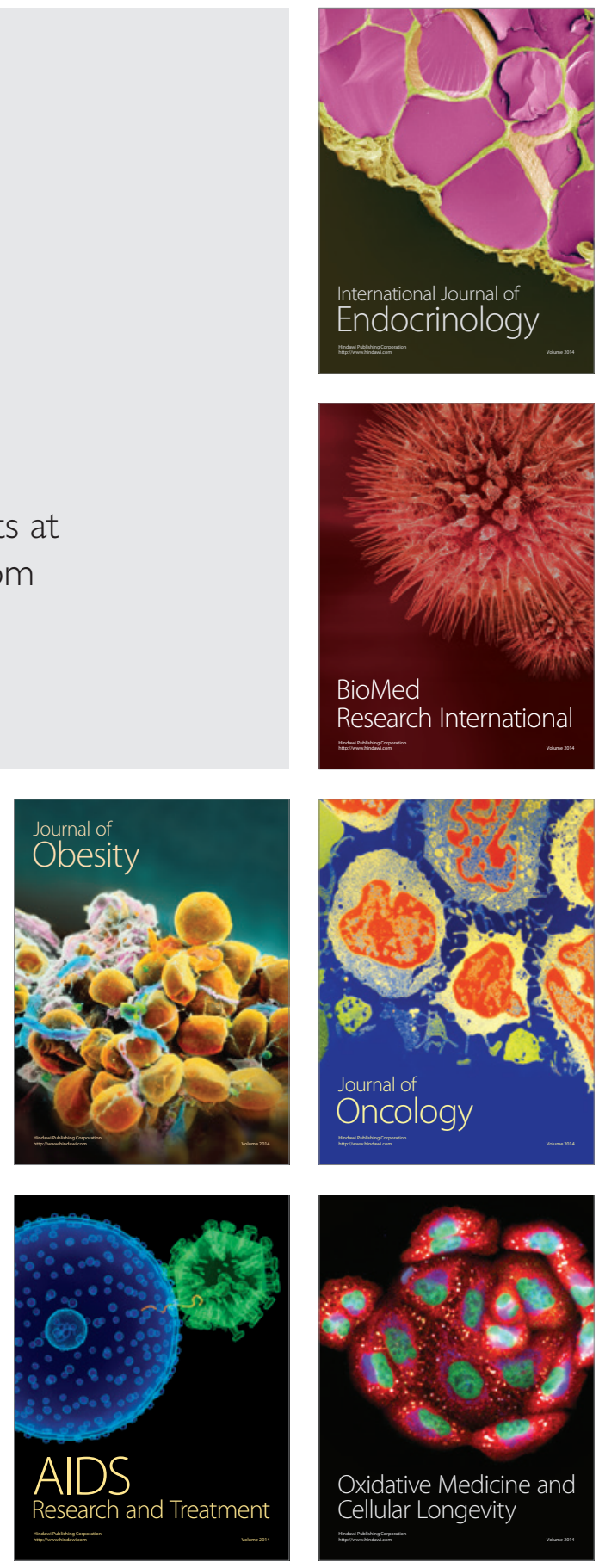